\title{
Case Study - Presence of Salmonella Species in Coconut after Kerala Flood2018
}

\author{
Abhinsha $Z^{1} \mid$ Dr. Noha $L^{2}$ \\ ${ }^{1}$ PG Student M.Sc Microbiology, A J College of Science and Technology, Thonnakkal. \\ ${ }^{2}$ Asst. Professor Microbiology, A J College of Science and Technology, Thonnakkal.
}

To Cite this Article

Abhinsha Z and Dr. Noha L, "Case Study - Presence of Salmonella Species in Coconut after Kerala Flood2018", International Journal for Modern Trends in Science and Technology, Vol. 06, Issue 05, May 2020, pp.: 105-107; https://doi.org/10.46501/IJMTST060518

\section{Article Info}

Received on 02-April-2020, Revised on 28-April-2020, Accepted on 10-May-2020, Published on 15-May-2020.

\section{ABSTRACT}

A case study that accidentally found Salmonella species, a very rarest case, from flood affected Cocosnucifera while processed in frozen food industry. Coconut is actually considered to be safe and contamination free because of its hard-outer covering, amidst the presence of highly nutritive water content. This was proved to be wrong after the identification of different species of bacteria from coconuts collected during the flood period and was identified during the routine tests.

KEYWORDS: Coconut, flood, Salmonella species, XLD agar, biochemical tests.

Copyright (C) 2014-2020 International Journal for Modern Trends in Science and Technology

DOI: https://doi.org/10.46501/IJMTST060518

\section{INTRODUCTION}

Foodborne diseases encompass a wide spectrum of illnesses and are a growing public health problem worldwide. They are the result of ingestion of foodstuffs contaminated with microorganisms or chemicals. The contamination of food may occur at any stage in the process from food production to consumption ("farm to fork") and can result from environmental contamination, including pollution of water, soil or air.

The most common clinical presentation takes the form of gastrointestinal symptoms; and can also have neurological, gynecological, immunological problems. Multiorgan failure and even cancer may result from the ingestion of contaminated foodstuffs, thus representing a considerable burden of disability as well as mortality. Salmonella is one of the major foodborne pathogens in worldwide. Salmonella are a group of bacteria that can cause gastrointestinal illness referred to Salmonellosis. CDC estimates Salmonella causes about 1.2 million illnesses, 23,000 hospitalizations, and 450 deaths in the United States every year. Food is the source of about 1 million cases of these illnesses. Most people infected with Salmonella develop diarrhea, fever, and abdominal cramps (SALMONELLOSIS) 6 hours to 4 days after infection. The illness usually lasts 4 to 7 days, and most people recover without treatment.

In some people, the illness may be so severe that the patient needs to be hospitalized. Cocosnucifera or coconutis a common drupe seen in Kerala.Coconut (Cocosnucifera) is packed with high nutrients, macro nutrients, vitamins etc. and so they are very much prone to contamination. Coconut has protective layers of exocarp, mesocarp making up the husk and the seed is protected by a 
stony shell endocarp and it is aseptic. Frozen shredded coconut is one of the major exporting products of coconut. There are many frozen food industries which are making great profits out of this. But after the Kerala flood of 2018, coconut collected from Palakkad and Ernakulam where highly contaminated with Salmonella and other organisms, thought to be the result of the contaminated flood water. Salmonella, Enteric bacteria and Coliforms have been isolated during the routine microbial analysis using Rappaport Vassiliadis Medium and Xylose Lysine Deoxycholate agar, which was further confirmed by biochemical analysis. This is one of the first studies which showed up the contamination by Salmonella and other organisms on "Cocos nucifera" (Schaffner et., al, (1)) through the penetration of contaminated water through the husk and shell. This study highly emphasis on the potential risk of obtaining Salmonellosis from the unprocessed raw coconut used as the raw material in food industry during 2018 Kerala flood (2)

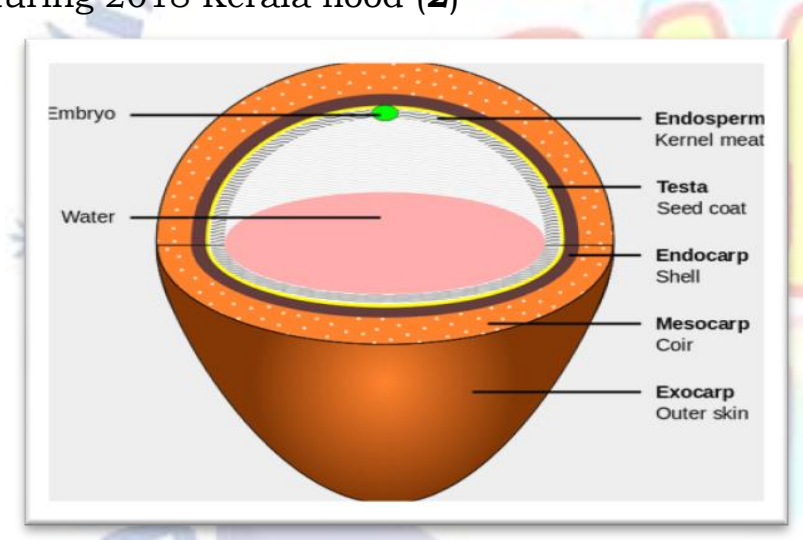

\section{Structure of Coconut}

\section{KERALA FLOOD 2018}

On 16 August 2018, severe flood affected the south Indian state Kerala, due to the unusual high rainfall during the monsoon season. Chengannur, Pandanad, Edanad, Aranm ula, Kozhencherry, Ayiroor, Ranni, Pandalam, Kut tanad, Malappuram, Aluva, Chalakudy, Thrissur, Thiruvalla,Eraviperoor, Vallamkulam, Chellanam, Vypin island and Palakkad these are the majorly affected areas .

The worst effect of flood is the accumulation of drainage water, sewage water, septic tank water, hospital waste etc through which diseases can spread quickly.

\section{Processing of Coconut}

In frozen industry "frozen grated / shredded coconut" is the demand product for exporting to foreign countries. The coconut from all over Kerala was collected for processing, mainly from Palakkad and Ernakulam.After flood about around 5 metric ton of coconut as raw material was collected from a seller and he procured the coconuts from Ernakulam and Palakkad.From primary quality check of raw material inspection, it was found that the outer shell had a huge amount of moisture content and the sample was then collected from the processing room and the routine test was done, which showed that it was high in contamination.

Variations in TPC was also found. The sample also showed the presence of Salmonella species, Enteric bacteria etc.Another sample was taken on the next day by selecting and screening the raw materials and run the test it again showed the same results. Even after the increase in the chlorination concentration, the results didn't change.On the third and final day of production the results were even worst, indicating the multiplication of Salmonella. The coconuts were then discarded without processing. After the enquiry with the details from the seller it was found that those coconuts where from the flood affected areas.

This was one of the rarest cases even after we consider the presence of husk which is able to protect the entire coconut, the contaminants breach through the protective layers and caused contamination.

Another sample was taken on the next day by selecting and screening the raw materials and run the test, the same results were found even after the chlorination concentration was increased.

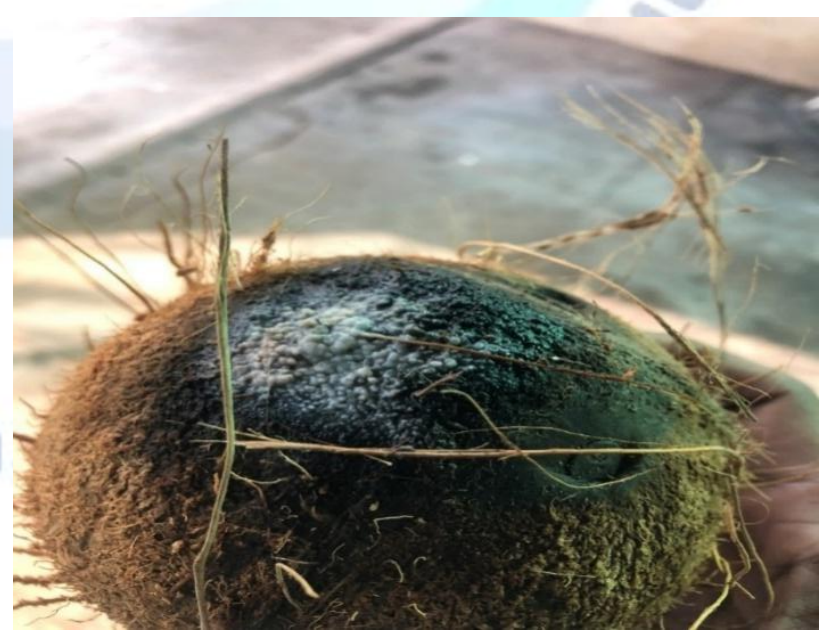

Contaminated Coconut from the outside 
Further microbiological procedures were carried out to confirm and the following results were obtained.

1. All the 3 dilutions $10^{-1}$ to $10^{-3}$ where found to be TNTC (too numerous to count), this indicates that the food cannot be consume directly and it is highly contaminated.

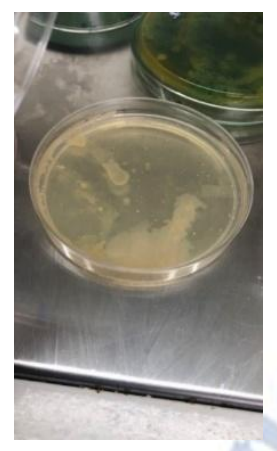

$10^{-1}$

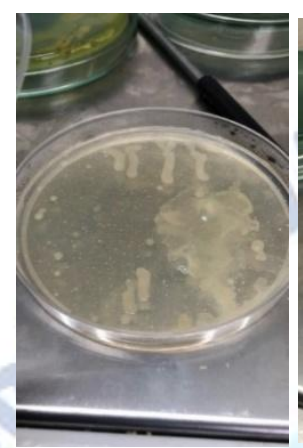

$10^{-2}$

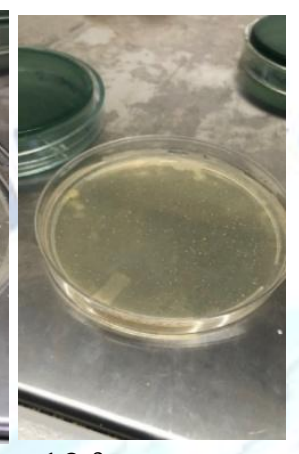

$10^{-3}$

\section{Colonies present in nutrient agar}

2. Mac Conkey agar for the detection of enteric bacteria (Edwards and Ewing (3)). Enteric bacteria were present in the sample of coconut. Enteric bacteria are bacteria are present usually in the intestines.

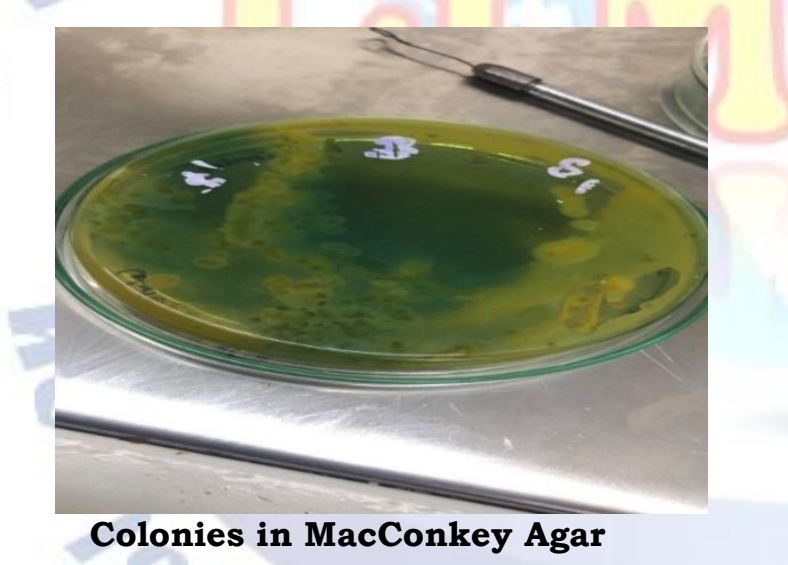

3. Salmonella identification can be grown using XLD agar (xylose lysine deoxycholate agar) (WHO, (4)). Salmonella was identified by colony morphology, black centred colonies are the Salmonella sps on XLD agar (Zajc-Satler and Gragas, (5)).

\begin{tabular}{|l|l|}
\hline \multicolumn{1}{|c|}{ Biochemical test } & \multicolumn{1}{c|}{ Results } \\
\hline On TSI slant & $\mathrm{R} / \mathrm{Y} / \mathrm{H} 2 \mathrm{~S}+\mathrm{g}^{+}$ \\
\hline Lysine decarboxylase & positive \\
\hline Citrate utilization & positive \\
\hline Urease & negative \\
\hline Motility & positive \\
\hline Indole & negative \\
\hline MR & positive \\
\hline VP & negative \\
\hline
\end{tabular}
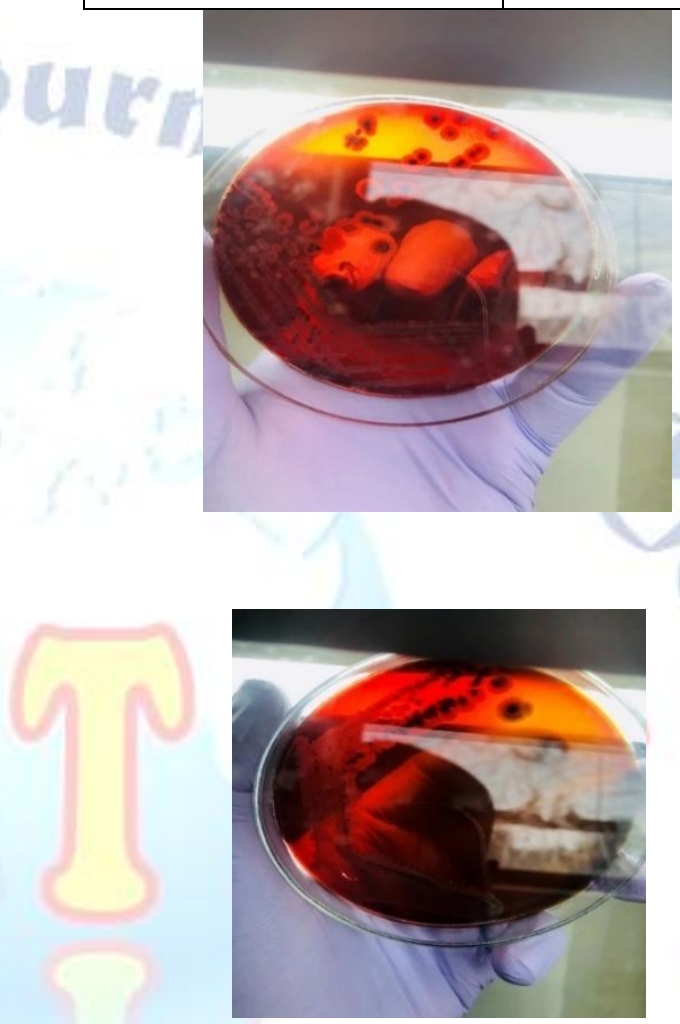

Colonies of Salmonella on XLD agar

4. Biochemical tests for the confirmation of Salmonella species

Presumptive positive colonies were characterized using secondary biochemical tests for the confirmation of the organism Thus, the organism was confirmed to be Salmonella sps. (WHO(6)).

The naturally aseptic Cocos nucifera gets contaminated easily through a flood. It was due to the presence of bacteria and other organisms in the flood that came through by various ways (like sewage waste, septic tanks, hospital wastes etc).

The husk of the coconut absorbed the contaminated flood water and that water causes the germination spores to decay and finally it enters into the coconut causing contamination. It was found that a single coconut can spoil the entire production with its contamination. Hence proper checking of the coconut is necessary before starting the processing.

\section{REFERENCES}


[1] Schaffner CP, Mosbach K, Bibit VS, Watson CH(1967 May;15). In: "Coconut and Salmonella infection". Pubmed Appl Microbiol. 1967 May;15(3):471-5.

[2] "Kerala floods: Death toll rises to 483, says CM Pinarayi Vijayan". New Indian Express. 30 August 2018. Retrieved 2 September 2018.

[3] Edwards, P. R. and W. H. Ewing. 1962. Identification of Enterobacteriaceae, 2nd ed. Burgess Publishing Co., Minneapolis.

[4] WHO Global Salm-Surv. Laboratory Protocol: Isolation of Salmonella. 5th Edition. 2007.

[5] Zajc-Satler J and Gragas AZ (1977). "Xylose lysine deoxycholate agar for the isolation of Salmonella and Shigella from clinical specimens". Zentralbl Bakteriol [Orig A]. 237 (2-3): 196-200.

[6] WHO Global Salm-Surv. Laboratory Protocol: Identification of Salmonella. 5th Edition 